\title{
Edukasi Deteksi Dini Kanker Payudara melalui Pemeriksaan Payudara Sendiri (SADARI) di SMA N 8 Kota Jambi
}

\author{
Nel Efni ${ }^{1}$, Tina Yuli Fatmawati ${ }^{2}$ \\ ${ }^{1}$ Program Studi S-I Keperawatan, STIKes Baiturrahim Jambi \\ ${ }^{2}$ Program Studi DIII Keperawatan, STIKes Baiturrahim Jambi \\ Email: nelefni2016@gmail.com
}

Submitted : 22/11/2020

Accepted: 06/12/2020

Published: 11/01/2021

\begin{abstract}
The highest incidence of cancer in Indonesia occurs in women: breast cancer and cervical cancer. The risk of breast cancer increases with age. Even a young age does not guarantee that it is safe from breast cancer. In basic health research, the highest number of cancer patients was Central Java, with 68,638 people with 11,511 cancer patients. Self-Breast Examination (BSE) is an integral part of every woman's breast examination. Breast self-examination is performed once a month and can be an effective screening instrument for breast lesions. The purpose of this activity is to inform breast cancer, its signs and symptoms, causes, prevention and how to detect breast cancer by means of BSE. This service activity was carried out in November 2019-January 2020, at SMA N 8 Jambi City. The target is 30 students. This activity consists of providing education using power point media, leaflets, posters and videos, as well as demonstrations using models. After education, all students can understand and be able to properly demonstrate BSE techniques. It is recommended that students routinely carry out breast self-exams every month so that they can detect early breast cancer symptoms.
\end{abstract}

Keywords: breast cancer, education, early detection, self breast examination

\begin{abstract}
Abstrak
Angka kejadian kanker tertinggi di Indonesia terjadi pada perempuan yaitu kanker payudara dan kanker leher Rahim. Resiko kanker payudara meningkat sesuai bertambahnya usia bahkan usia muda tidak menjamin aman dari kanker payudara. Dalam riset kesehatan dasar, jumlah penderita kanker terbanyak adalah Jawa Tengah sebesar 68.638 orang dengan jumlah penderita kanker sebesar 11.511 orang. Pemeriksaan Payudara Sendiri (SADARI) adalah bagian yang tidak terpisahkan dari pemeriksaan payudara setiap wanita. Pemeriksaan payudara sendiri dilakukan setiap 1 bulan sekali dan dapat menjadi instrumen penapisan yang efektif untuk mengetahui lesi payudara. Tujuan dari kegiatan ini adalah menginformasikan penyakit kanker payudara, tanda dan gejalanya, penyebab, pencegahan serta cara mendeteksi kanker payudara dengan cara SADARI. Kegiatan pengabdian ini dilaksanakan pada bulan November 2019-Januari 2020, di SMA.N VIII Kota Jambi. Sasaran adalah siswi sebanyak 30 orang. Kegiatan ini terdiri dari pemberian edukasi dengan media power point, leaflet, poster dan video serta demonstrasi menggunakan model. Setelah dilakukan edukasi seluruh siswi dapat memahami dan mampu mendemonstrasikan tehnik SADARI dengan benar. Disarankan kepada siswi agar rutin melakukan pemeriksaan payudara sendiri setiap bulan agar dapat mendeteksi secara dini gejala kanker payudara.
\end{abstract}

Kata Kunci: edukasi, deteksi dini, kanker payudara, tehnik pemeriksaan payudara sendiri

\section{PENDAHULUAN}

Angka kejadian kanker tertinggi di Indonesia terjadi pada perempuan yaitu kanker payudara dan kanker leher Rahim.
Resiko kanker payudara meningkat sesuai bertambahnya usia bahkan usia muda tidak menjamin aman dari kanker payudara. Berdasarkan riskesdas 2013, jumlah 
penderita kanker terbanyak adalah Jawa Tengah sebesar 68.638 orang. Sedangkan penderita kanker terbanyak adalah kanker payudara dengan jumlah penderita kanker payudara di provinsi Jawa Tengah sebesar 11.511 orang (Kemenkes RI, 2015).

Skrining untuk kanker payudara adalah mendapatkan orang atau kelompok orang yang terdeteksi mempunyai kelainan/abnormalitas yang mungkin kanker payudara dan selanjutnya memerlukan diagnosa konfirmasi. Skrining ditujukan untuk mendapatkan kanker payudara dini sehingga hasil pengobatan menjadi efektif; dengan demikian akan menurunkan kemungkinan kekambuhan , menurunkan mortalitas dan memperbaiki kualitas hidup(level -3). Salah satu skrining yaitu dengan periksa payudara sendiri ( SADARI)( Kemenkes RI)

SADARI adalah bagian yang tidak terpisahkan dari pemeriksaan payudara setiap wanita. Pemeriksaan payudara sendiri dilakukan setiap 1 bulan sekali dan dapat menjadi instrumen penapisan yang efektif untuk mengetahui lesi payudara (Soemitro, 2012:144). Manfaat periksa payudara sendiri (SADARI) adalah untuk mendeteksi sedini mungkin adanya kelainan pada payudara karena kanker payudara pada hakikatnya dapat diketahui secara dini oleh para remaja wanita. Setiap wanita mempunyai bentuk dan ukuran payudara yang berbeda, bila wanita memeriksa payudara sendiri secara teratur, setiap bulan setelah haid, wanita dapat merasakan bagaimana payudara wanita yang normal. Bila ada perubahan tentu wanita dapat mengetahuinya dengan mudah (Sari, 2012)

Pemeriksaan payudara sendiri (SADARI) dapat dilakukan setelah seorang wanita mendapatkan menstruasi. Pemerikssaan payudara sendiri (SADARI) ini bertujuan untuk mendapatkan tanda kanker payudara pada stadium yang lebih dini (down staging)(Manuaba, 2010). Dengan SADARI ini perempuan dapat melakukannya secara mandiri tanpa mengeluarkan biaya untuk melakukannya serta dapat meningkatkan kesadaran dan kewaspadaan adanya suatu benjolan yang tidak normal pada payudara.Alasan lain mengapa perempuan tidak melakukan atau kurangnya motivasi untuk melakukan pemeriksaan payudara sendiri dikarenakan mereka merasa takut apabila setelah melakukan pemeriksaan payudara sendiri, perempuan menemukan suatu benjolan yang tidak normal pada payudaranya. Hal tersebut sebenarnya dapat membantu seorang perempuan mendapatkan terapi secepat mungkin sebelum kanker menjadi stadium lanjut (Soemitro, 2012).

SMA.N VIII Kota Jambi merupakan salah satu Sekolah Menengah Atas yang berada di Kecamatan Kota Baru dengan Jumlah siswi kelas XI sebanyak 240. Berdasarkan survei yang dilakukan pada bulan Agustus 2019 di SMA.N VIII kepada 4 orang remaja putri tentang pengetahuan dalam melaksanakan deteksi dini kanker payudara melalui SADARI, ke empat remaja tersebut tidak mengetahui kapan dilakukan pemeriksaan sadari dan bagaimana cara mendeteksi dini kanker payudara melalui SADARI sehingga tidak pernah melakukan SADARI. Salah satu guru juga menjelaskan jarang dilakukan penyuluhan kesehatan khususnya tentang SADARI. Guru sangat berharap agar dapat dilakukan pendidikan kesehatan khususnya tentang deteksi dini kanker payudara melalu SADARI sehingga siswi di SMA N 8 dapat memahami dan dapat menerapkan di rumah.

Upaya pemberian pendidikan kesehatan tentang pemeriksaan payudara sendiri remaja putri ini sangat diperlukan untuk pencegahan terjadinya kanker payudara. Menurut Notoatmodjo (2012), pendidikan kesehatan merupakan upaya untuk mempengaruhi dan juga mengajak individu, keluarga, kelompok maupun masyarakatuntuk melakukan perilaku sehat. Pemberian pendidikan kesehatan akan mempengaruhi atau menggerakkan 
seseorang agar timbul kemauan untuk melakukan sesuatu.

Berdasarkan fenomena diatas dan menyadari pentingnya upaya pencegahan pada remaja tentang deteksi dini SADARI ini maka tim mengadakan kegiatan edukasi tentang tehnik SADARI di SMA N 8 Kota Jambi.

\section{TARGET DAN LUARAN}

Target pada pengabdian ini adalah terjadi peningkatan pengetahuan siswi SMA N kelas X tentang deteksi dini kanker payudara dan tehnik SADARI sebesar $100 \%$. Adapun luaran selain jurnal adalah siswi dapat melaksanakan praktik SADARI dirumah serta dapat mengajarkan ke teman/keluarga terdekat.

\section{METODE PELAKSANAAN}

Metode yang digunakan dalam program ini adalah memberikan penyuluhan/edukasi dan demostrasi tentang Deteksi dini kanker payudara dengan SADARI . Sasaran pengabdian adalah perwakilan dari siswi kelas X dan XI yang dilaksanakan pada bulan Januari 2020 dan bertempat di ruang kelas SMA N 8 dibantu oleh 4 orang mahasiswa/i SI Keperawatan. Tujuan dari kegiatan ini adalah menginformasikan penyakit kanker payudara, tanda dan gejalanya, penyebab, pencegahan serta cara mendeteksi kanker payudara dengan cara SADARI. Tindak lanjut dalam kegiatan ini diharapkan remaja putri akan melakukan Sadari di rumah masing-masing dan melaksanakannya secara rutin setiap bulannya. Selain itu, diharapkan juga agar peserta penyuluhan yang hadir dapat mengajarkan pada siswi lain sehingga siswi khususnya di SMA N 8 dapat mendeteksi kanker payudara secara dini. Adapun pelaksanaannya dilaksanakan dalam beberapa tahap sebagai berikut :

\section{Tahap Pertama}

Tahap pertama merupakan perencanaan kegiatan dilakukan. Proses perencanaan meliputi identifikasi kebutuhan, identifikasi potensi dan kelemahan yang ada, menentukan jalan keluar, rencana kegiatan yang akan dilakukan, dan membuat pengorganisasian kegiatan. Pada tahap ini tim berdiskusi dengan ssalah satu guru BK

\section{Tahap Kedua}

Tahap kedua merupakan pelaksanaan kegiatan. Pada tahap ini metode yang digunakan ceramah, diskusi, Tanya jawab dan demonstrasi tentang tehnik SADARI.

\section{Tahap Ketiga}

Pada tahap ketiga, dilakukan monitoring dan evaluasi kegiatan. Evaluasi dilakukan secara kontinyu mengenai sejauh mana progres perkembangan kemajuan program kegiatan berdiskusi dengan tim pelaksana serta guru BK.

\section{HASIL DAN PEMBAHASAN}

Kegiatan pengabdian ini diikuti oleh 30 orang peserta yang merupakan remaja putri /siswi SMA N 8 Kota Jambi. Kegiatan penyuluhan dilaksanakan pada bulan Januari 2020 bertempat diruang kelas. Pemberian materi penyuluhan dengan menggunakan LCD, video, PPT Kemudian peserta penyuluhan diberikan leaflet tentang Deteksi dini kanker payudara dengan tehnik SADARI, yang dapat digunakan sebagai acuan pemeriksaan SADARI di rumah. Selama penyampaian materi, para peserta menyimak dengan antusias. Setelah selesai menyampaikan materi dibuka forum tanya jawab mengenai materi yang telah disampaikan. Ada beberapa pertanyaan yang diajukan oleh peserta yang terkait dengan pencegahan kanker payudara dan bagaimana langkah-langkah pemeriksaan SADARI.

Penyuluhan kesehatan adalah kegiatan pendidikan yang dilakukan dengan cara menyebarkan informasi-informasi pesan, menanamkan keyakinan, sehingga masyarakat sadar, tahu dan mengerti, tetapi juga mau dan bias melakukan suatu anjuran yang ada hubungannya dengan kesehatan serta terjadi peningkatan pengetahuan, keterampilan, dan sikap. Salah satu alat 
bantu dalam penyuluhan kesehatan adalah leaflet, video, model. (Notoatmodjo, 2012).

Kesadaran tentang pentingnya upaya preventif terhadap penyakit khususnya Kanker Payudara belum mendapat perhatian serius. Satu-satunya cara yang paling efektif yang dapat dilakukan untuk deteksi dini kemungkinan timbulnya penyakit ini adalah dengan melakukan pemeriksaan payudara sendiri. SADARI adalah suatu prosedur untuk mengetahui kelainan-kelainan pada payudara dengan melakukan inspeksi secara berkala, misalnya sebelum melakukan pemeriksaan payudara terlebih dahulu harus mencuci tangan agar tidak terjadi infeksi pada payudara, serta penggantian bra merupakan salah satu dari penanggulangan untuk pencegahan infeksi pada payudara. Adapun tujuan dilakukannya SADARI adalah untuk mendeteksi adanya kelainankelainan pada payudara baik struktur, bentuk ataupun tekstur (Soemitro, 2012). Para wanita disarankan untuk melakukannya sendiri karena mereka sendiri yang benar-benar mengenal struktur payudara normalnya. Oleh karena itu jika ada benjolan atau ada hal normal lainnya, maka mereka akan langsung menyadarinya.

Pemberian pendidikan kesehatan tentang SADARI diharapkan dapat memberikan dampak positif bagiremaja putri,pengalaman serta pengetahuan dalammenangani deteksi dini Kanker payudara.

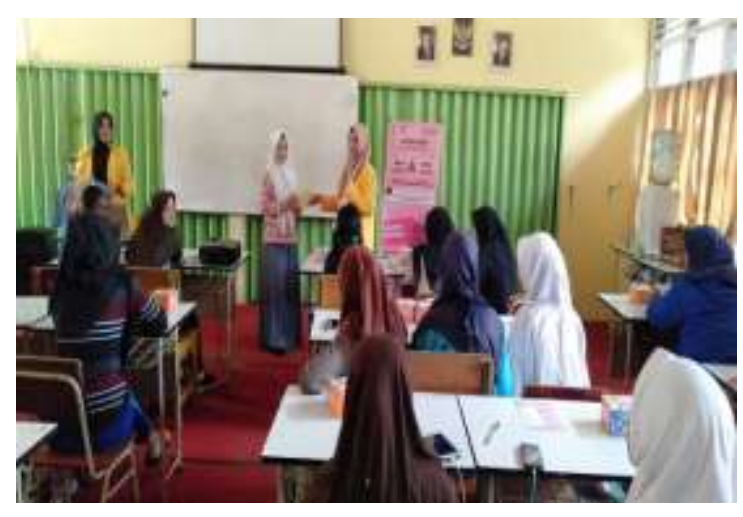

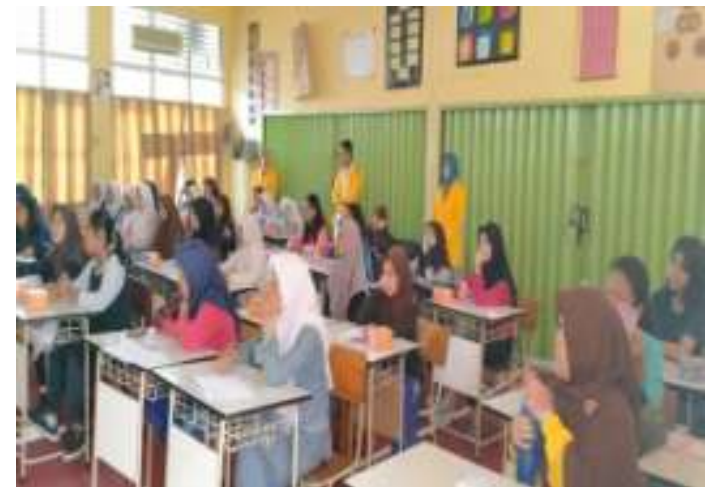

Gambar 2. Kegiatan penyuluhan

\section{KESIMPULAN DAN SARAN}

\section{Kesimpulan}

Setelah dilakukan kegiatan penyuluhan dan pelatihan mengenai pemeriksaan SADARI menggunakan video, pembagian leaflet SADARI dan praktek langsung SADARI maka terjadi peningkatan pengetahuan dan ketrampilan siswi tentang SADARI di SMA N 8 Kota Jambi

\section{Saran}

Diharapkan siswi agar rutin setiap bulan melakukan pemeriksaan sadari secara mandiri dirumah, sehingga dapat mengetahui dan mencegah terjadinya kanker payudara. Peserta juga diharapkan mau menyebarluaskan pengetahuan tentang kanker payudara dan metode SADARI pada teman teman sekolah, anggota keluarga lain dan masyarakat sekitar

\section{DAFTAR PUSTAKA}

Kementrian Kesehatan RI Pusat Data dan Informasi Kesehatan. Infodatin, diakses Agustus, 2019

Kementrian Kesehatan RI, Panduan penatalaksanaan kanker payudara. http://kanker.kemkes.go.id/guidelines /PPKPayudara.pdf

Maulana. (2009). Promosi Kesehatan. Jakarta: EGC

Murwani, A. (2014). Pendidikan Kesehatan Dalam Keperawatan. Yogyakarta: Fitramaya

Gambar 1. Kegiatan Penyuluhan 
Notoadmodjo, 2012. Promosi Kesehatan dan Perilaku Kesehatan. Jakarta: PT Rineka Cipta

Pratiwi. 2011. Buku Pintar Kesehatan Wanita. Imperium. Jogjakarta

Rasjidi, I. 2009. Deteksi Dini \& Pencegahan Kanker Pada Wanita. Sagung Seto. Jakarta

Russel, M, D. 2011. Bebas Dari enam Penyakit Mematikan. Medpress. Jogjakara
Sanddina, D. 2011. Sembilan Penyakit Mematikan.Smart Pustaka.Jogjakarta Sari, dkk. 2012. Kesehatan Wanita. Swadaya Salemba. Jakarta

Sjamsuhidayat. 2011. Bebas Dari enam Penyakit Mematikan. Medpress. Jogjakara

Soemitro, M. 2012. Blak-Blakan Kanker. Jogyakarta: Graha Qinita

Susilo, R. (2011). Pendidikan Kesehatan Dalam Keperawatan. Yogyakkarta: Nuha Medika 